\title{
Simulating the Meaning and Meaning of the Simulation: New Narrative Strategies in the Video (Analysing the Clip "Iridescent" by Linkin Park)
}

\author{
Francisca Foortai \\ Faculty of Philosophy, Culturology and Art, Leningrad state University Named After A. S. Pushkin, St-Petersburg, Russia
}

\section{Email address:}

ira_oza@msn.com

\section{To cite this article:}

Francisca Foortai. Simulating the Meaning and Meaning of the Simulation: New Narrative Strategies in the Video (Analysing the Clip "Iridescent” by Linkin Park). History Research. Vol. 9, No. 1, 2021, pp. 31-38. doi: 10.11648/j.history.20210901.14

Received: November 11, 2020; Accepted: December 8, 2020; Published: February 20, 2021

\begin{abstract}
What kind of narrative games does cinema play?" - These questions are particularly relevant in relation to such a cinematic phenomenon as the clip, which by the end of the XX century formed into a quasi-short film, which is a synthesis of web design and cinema, and is an ontological borderline of the film text. One of the latest narrative strategies with a flourish featured in the Linkin Park video for the main soundtrack of the movie "transformers 3: Dark side of the moon. The entire movie text of the clip is a manifestation of the hyperreal in all its features: empty no space, relatable discrete time, visual simulacra, devoid of its own meaning, but simulating similarity to images of real cinema. Moreover, the clip is full of so-called Semo-simulations, i.e. signs that are similar in outline to the signs of the ancient civilizations of Egypt and Sumer, but they are not, i.e. there is no meaning behind these figures. However, if all of the above complete content of the clip-this work would not make sense. In the video, there is a "third element" (Eisenstein) because all the Grand visual simulation created within the Hyper/art, which is cinema, met with poetic text and music. The poetry and music of the song "Iridescent" come into conflict, almost in denial of what is unfolding on the screen. The very name of the song "Descended from the rainbow" refers to the old Byzantine and Orthodox icons on which Christ depicted sitting on a rainbow, the entire text of the song is an internal monologue, turning to God for help after disappointments, losses, and spiritual devastation. It is the music track and the text that are the elements of existence that finally bring the narrative of the video to the realm of intellectual phantoms, which gives the audience a sense of freedom, the presence of a higher good force and true human reality, which (for now?) simulacra and simulations of meaning will not destroy it.
\end{abstract}

Keywords: Narrative Strategies, Movie Text, Music Video, Creolized Text, Simulacrum, Simulation, Hyper/Art

\section{Introduction}

The narrative as a cultural phenomenon essentially assumes the construction of actions and events (historical or particular) in a certain logical sequence, with the help of actors who are "inside" the narrative and the narrator, who interprets events to a greater or lesser extent in line with his mental strategy. Cinema, which emerged in the industrial era, took on a function somewhat in tune with the task of the "Bible for the illiterate" of medieval cathedrals, i.e., to tell stories by showing pictures (the pictures were moving, and the stories were not only from Sacred history). Having taken up storytelling, cinema did not remain long in the field of documenting events, but at an early period began to construct narratives using socially relevant information in order to conduct thought experiments and play different types of behavior and different scenarios. How does the transformation of history, big and small, someone else and your own, turn into a movie narrative? What are the narrative strategies used by the cinema, designing a particular space and time? Especially interesting and relevant, in our opinion, are these questions about such a cinematic phenomenon as a clip, which by the end of the XX century was formed into a quasi-short film, which is a synthesis of web design and cinema, which is the ontological border of the film text, behind which the viewer loses the psycho-emotional and physiological ability to perceive a visual image.

In one of his works, Vitaly Kurennoy [1] developed a 
method for studying modern cinema, which involved refusing to evaluate the aesthetic component of cinema (the originality and quality of Director's work or acting). First, the visual structure of the film, the images and symbols used in it, and other methods of translating the main meaning of the film are evaluated. Kurennoy considers cinema as one of the types of mass culture, and therefore its main cultural units are not elite films of the art-house series, but blockbusters that embody the main stereotypes, behavioral strategies and values of modern society. To the full extent, the clip must also be included here, in addition to blockbusters. The entire set of clips, including the existing genres-music, advertising, news, art (trailer), we propose to designate the term «clipping» [2] which is a mechanism for virtualizing fragments of reality and, at the same time, is one of the ways to deploy hyper reality. Clipping is a global mechanism for aestheticizing of simulacra, whose specific features are enigmatism, associativity, and hyperbolization of the sign. The field of existence of clipping is a virtual game with signs indicating fragments of reality and artistic realities, during which the subject is its passive spectator. Among the genres of music videos, the music video is not only the «oldest» of them, but also the most complex and interesting in terms of building a movie narrative.

The music video as a type of movie exists more than half a century. On December 26, 1967, an unusual television movie premiered in England. What was unusual about it was that the plot of the film dictated by the music album, or rather, the TV video series was a kind of «live picture» to the music of the Beatles «Magical Mystery Tour» album. Six months later, at the London palladium on July 17th, 1968, the premiere of Heinz Edelman's cartoon «Yellow submarine» took place, in which for the first time real personalities appeared as their virtual counterparts. As well as «Magic mysterious Tour», this film «illustrated» Beatles compositions from the albums «Revolver» and «Yellow Submarine». David Cook, in a book dedicated to cinematic narrative, writes that the first music video broadcasted on TV was the video for the Beatles song "Paperback writer" as part of the Ed Sullivan show. [3] Although attempts to analyze the clip and the phenomena that anticipated its formation date back more than a decade, (one of the first works in this field is book of Suzanne Langer -one can see a certain one-sidedness in these studies. [4] They usually dealt with the social and psychological aspects of the clip. Among the evaluation characteristics of music videos, there are often such judgments as - fast, empty, lustful. At least, that is how most of the academic world sees it. Using Frederick Jameson's terms, a music video can be defined as "a schizophrenic motif of isolation, interrupted meanings, collapsing sequences of meanings, a string without attachment». [5] Andrew Goodwin speaks of "semiotic pornography», "electronic wall newspaper», and «neo-fascist propaganda». [6]

At the same time, one of the participants of the first Russian theoretical seminar «Clip as a leading language of mass communication: the possibilities and limits of Analytics» (Saint Petersburg, 2002), K. V. Golovko noted that the clip can be considered as «a virtual space that gives a special status to all manifestations of everyday life, which in other conditions do not claim to be full and important... Without corresponding to any hierarchy, it is a medial chaos of certain images... reflections of the real world». [7]

Such different assessments of the clip as a mass media phenomenon are due not only to its technical and technological complexity and figurative and artistic synthetization, but also to the fact that the visual text of the clip is the most complex form of film text.

\section{Theoretical Base}

Any text, including the video text of a clip, in order to be such (i.e., a text) must build its own narrative to express certain meanings that the audience can "read" and understand. If we proceed from the statement that "constructing narratives is a cognitive game with socially significant information», then the attention to clipping products should be quite close, since many of them watched by a much larger number of viewers than full-length films. The development of digital technologies has contributed to the fact that in our time, the most popular, and mass, at the same time, democratic form of cinema has become a clip in all its variety of genres, among which the music video occupies a leading place. In addition, the strength and duration of the impact also related to the fact that the vast majority of clip consumers are the young population of the planet, which is more susceptible to various external influences, including aesthetic, therefore, the social, aesthetic and mental impact of clip products on modern society is more widespread. It is also impossible to ignore the fact that after (before) the premiere of the clip on TV or on the radio, it appears on YouTube, which has become the most popular video hosting and the second site in the world by the number of visitors, due to its simplicity and ease of use.

The peculiarity of the visual language of the clip is such that it is able not only to widely and artistically appeal to translate mentalities and behavioral norms, but also to encourage the practical implementation of the provisions of a particular philosophical (ideological) teaching, thus bringing virtual representations into the sphere of social action. Metaphorically speaking, the reality created by clipping look like to the Ocean on the planet Solaris from the novel of the same name by S. Lemm and the film by A. Tarkovsky, who not only fed on the feelings, thoughts and images of people, but also built his own reality on their basis, his similar but different world.

The second thing that puts the clip in the focus of modern narrative film strategies is that, in our opinion, the visual text of the clip is the most complex form of creolized text.

The first attempts to conceptualize film making as a sign system, as a text were made by theorists of the Russian formal school and Yu. Tynyanov and V. Shklovsky. Tynianov in the work «On the fundamentals of cinema» (1927) proposed a description of the «vocabulary» of cinematic storytelling, highlighting as meaningful units of visual language movie following figures - cinema epithet, cinema 
metonymy, cinema synecdoche, as well as «grammatical» methods - influx, angle, aperture, rule of following plans.

The next stage in the development of the concept of film text was the theory of editing by S. Eisenstein. In his later works, in particular, «Not Indifferent nature» (1945-1947), he develops a peculiar philosophy of film editing as a synthetic way of producing meaning.[8] The basic algorithm for «value production» is a comparison of two elements, in which, based on their formal properties, «a third element» appears that is qualitatively superior to both of the original ones. This algorithm is both verbal (in terms of poetic language and its basic unit - metaphor) and visual (the principle of intraframe and inter-frame editing).

Finally, the term creolized text formulated. It belongs to the Russian linguists Yu. A. Sorokin and E. F. Tarasov. In their opinion, creolized texts are «texts whose texture consists of two inhomogeneous parts - verbal (language, speech) and non-verbal, which belong to other sign systems than natural language» [9] It is obvious that among the creolized texts that have triumphed in the culture, the leading place belongs to the movie text, and in the movie text the highest degree of creolization is achieved in the clip.

\section{Selecting an Object for Analysis}

Choosing the video «Iridescent» by the American multiplatinum group Linkin Park as a concrete example for understanding modern narrative strategies, the author was guided not only by the artistic weight of this group, but also by its socio-cultural significance. To date, we can say that for eighteen years of the band's existence, a whole subculture of LP has developed, which has a planetary scale, and includes more than hundred million music discs, official websites, a social network system, an economic component (production and sale of hoodies, vests, caps, badges, bracelets, bags, phone cases, etc.), a network of salons Club Tattoo, TV and radio channels, their "ambassadors" - envoys in various countries. The external view of the band members influenced the style of youth clothing, hairstyles, and accessories.

In this socio-cultural aspect, the premiere of the clip «Iridescent», which took place on June $3 \mathrm{rd}, 2011$ on MTV, was worldwide. The video was a success, reaching 2-3 places in the music charts of the United States, Great Britain, and South Korea, entering many countries in Europe, America and Asia in the top ten video hits. The number of views of the video estimated in the tens of millions in many countries, not counting impressions on music channels, and this is much more than the audience of a normal full-length movie. The video received rave reviews both in the music press and among film critics, noting the «cinematography» of the clip, the quality of its special effects, and, in particular, the unusual narrative strategy.

Perhaps the extended metaphor of Jorge Luis Borges's story about «the garden of diverging paths» applies to the video's narrative. Indeed, the narrative «paths» of the clip «Iridescent» look intricate and almost do not intersect with each other, since the musical and poetic text, at the first glance, do not have semantic echoes with the film text, the installation of which, both inter-frame and intra-frame, takes place without taking into account logical development, linear narration, and even obvious meaning.

This clip from music innovators who use in their work not only advanced technical means, but also the latest visual strategies, like a smartphone that combines the functions of a phone, telegraph, a calendar, a camera, a notebook, TV, a movie camera, a player and a tape recorder under one form appears as a synthetic multifunctional object. This fourminute short film is not only a music video for the song from Linkin Park's album «Thousand suns», but also appears as a trailer for the third part of the famous fantasy Saga «Transformers 3: Dark side of the moon!», as the song «Iridescent» was the main soundtrack of the film. Consequently, the clip also performs the function of an aesthetic object, and the functions of commercials, and the «visual packaging» of the film.

If you approach the addition of this clip-from the standpoint of classical narration when there are present reasons, the development of these circumstances, a climax, and consequences logically arose after the development of the events in the first impression of the image of the clip brings to mind the words of one of the participants of the first Russian theoretical seminar on the problems of clipping on the medial chaos of some images. What images are reflected in the pile and is it chaos? Or is this a new narrative strategy? It is logical to assume that the new narrative should reflect the new features of reality.

\section{Features of the Reality Reflected in the Clip}

Feature 1. Content. The clip has a plot, i.e. a certain sequence of frames-pictures, but it does not have a plot, i.e. an internal mechanism for development, goal setting. In this aspect, the clip, to some extent, resembles a working machine: it works (the plot), but there is no future, goal setting in the car itself (there is no plot). Before us (at first glance) unfolds a movie text without meaning, i.e. a simulation of the narrative.

From the very beginning of creating the video, the idea was formulated by the Director (band member Joe Hahn) in the key of creolization-no matter what, the main thing is how! The idea formulated very succinctly, from the point of view of visual appearance: «in the valley of the blind, there is a one-eyed king, horns grow from his shoulders, and white dogs and snakes live near the throne». Who is not present in the clip: a one-eyed king with horns growing from the shoulders, a crowd of short people, in the form of swaddled mummies, transformers Autobots Optimus Prime, Bumblebee, Septinell Prime, Megatron, their opponents the Decepticons, the entire Linkin Park, snakes and dogs. all «actors» do not actually act, they appear and disappear again. And if each group of these «faces» is presented as a separate story, as a «narrative path», then each of them occurs several 
times, representing an intermittent, bizarre trajectory, where there is no logical beginning and logical end. These discrete quasi-narratives almost do not intersect with each other. Where do these quasi-narrative trajectories unfold? What unites (and does it?) are they integrated?

Feature 2. Space. From a visual point of view, the clip space is a kind of black extension, in which there is no support, top, bottom, or any other characteristics that correspond to real spaces. I remember the metaphor of F. Jameson's «string without attachment», which fully reflects the quality of the space presented in the clip. Here nothing is supported by anything, everything and everyone inside this space is sitting, flying, running, standing, hanging by themselves, regardless of spatial characteristics. Black color and indefinite length and depth, as well as showing the lunar surface on which the Decepticons and Autobots land, should make it clear that this is «space of cosmos», but finding a large number of strange characters and quite real dogs and snakes in it even the most non-reflective viewer makes it clear that this is not a simulation of outer space, but a simulation of space in general, as one of the categories of reality.

Since the artistic space of the clip is hyperreal in its ontology, it has a property inherent in this type of space, namely, its length measured by time. By its length, the artistic space of the clip is quasi-short, that is, in essence, it is the ultimate timing for visualizing an artistic image. In the absence of drama and plot mechanisms of action, the artistic space of the clip is collected (in association with the game of beads by G. Hesse or the assembly of models by H. Cortázar) from discrete microspaces of frames, among which the role of denotation as a reference to the signified reality is played by a musical work, creating a long series a number of cultural connotations, ranging from scholastic ideas about the primacy of sound in the arts and the secondary nature of illusory visual images to the absolute darkness of the province of Abkhazia in one of the novels by U. Eco in which the only connection to reality was sound. [10] Perhaps such a heterogeneous, discrete structure of space can be designated by modern term «polylocality». At the same time, it seems to us that such spatial characteristics took place long before the appearance of the system of representation of artistic images in the space of hyperreality. This means that the space of the myth, which was "torn", was heterogeneous in its subject-object relations, in its temporal speed. So, in the case of a music video, it is more correct, despite the "polylocality" of its artistic space, to talk about another manifestation of the new archaic.

However, unlike the diverging paths of Borges`s garden, the clip has one "place" where almost all the characters of the clip meet, where most of the narrative paths converge. This is a visual allusion to Leonardo da Vinci's famous Milan mural "The Last Supper", which appears in the clip four times (more than a minute in total, for a 4-minute film that is a lot!). At a table that resembles the Easter table of Christ and his apostles, hanging in a strange black void, there is a oneeyed king and his magical, some with angelic wings, courtiers (they are also participants in Linkin Park), swaddled mummies-short men who serve at the table, snakes and dogs. There is a bowl on the table that looks like a communion Bowl, but there are snakes crawling on the same table. This is a kind of center of most of the space where almost all the actors of the clip meet.

This invented, fantastic length is several times «torn» by the same inhomogeneous and unreal space of the "moon", on which the transformers land. The paradox in the interaction of these two spaces is that "moonscapes" with transformers are frames from the film, part of the chronicle from the transformers Saga, i.e., relative to the space in which all the other characters appear, it is a kind of "documentary footage". It seems to us that here we can talk about different levels of hyper reality, in particular, about the simultaneous presence in the narrative of the clip of a spatial simulation (episodes with Autobots and Decepticons) and a spatial simulacrum (the rest of the "fairy-tale" frames).

Feature 3. Time. It already been noted that a clip is a form of cinematic presentation, in which the frames are changed with a marginal rate of perception, beyond which the visual ambient begins, losing the sign of artistic and semantic. At the same time, the internal speed can be different and has multidirectional vectors of movement: in the past documentary, in the past artistic, in the future, variable present. External visual signs of the clip's narrative point to a futurological vector, namely, the simulation of outer space, but the presence of Linkin Park participants in the clip adds an element of relevance to the temporal vector, but not actual relevance, but artificially imagined. In contrast to space-and the clip as a cinematic artifact has only an internal, artistic space-time of the clip which is dual, in the sense that its narrative is limited to both real, physical time ( 4 minutes, 5 seconds) and" internal", artistic time, which is utopian and does not bear any principles of correlation, neither with historical links, nor with values, nor with the internal drama of the film text. The time of the clip is the "fourth phase of the performance", described by J. Baudrillard in his work about which he wrote that in this phase the image (including its temporal characteristics) does not relate to any reality at all: it is a pure simulacrum. [11]

However, this simulacrum preserves one of the attributes of time - the next sequence. This sequence does not follow the laws of cause and effect, it is illogical, meaningless, but it is there. Moreover, the visual range of this sequence, i.e. the speed of "time" is very intense. The film text of this 4-minute short film is extremely "dense" and in terms of technical characteristics-for 4.05 minutes of screen time on the screen, 67 monemas have passed, inside each 2-3 kinemas (whereas, for example, in a feature film, from 7 to 10 monemas pass on the screen during the same time). And from the point of view of the imaging textures (here and shooting on location of group members and animals, in particular dogs-pit bulls and snakes, and footage from the third part of the movie "transformers 3: Dark side of the moon", and computer graphics with special effects and costume theatre crowd) and "accommodation", i.e. the duration of the presence in the frame of each of the actors of the clip - the narrative clip is 
very fast. Metaphorically speaking, the life in the frame of each character in the clip is like a fluctuation of microparticles that appear out of nowhere without any logic and also inexplicably disappear in this black void.

Feature 4. Incomplete realities. In the complicated structure of the visual text of the clip, there is another sign of modern reality, namely the "shadow" of incomplete reality. These are fragments from the third part of the movie Saga about transformers, which is an adaptation of one of the modern hypermyths. [15] Hypermyth about transformers, created by the fantasy of Michael Bay more than 30 years ago based on the series of toys of the company "Hasbro" and the animated series of the same title. In terms of content, the hypermyth about tranformers is a post/apocalyptic chronicle that after the death of the home planet of Cybertron. The "good" Autobot robots are in a deadly confrontation with the mutant robots of the evil Decepticons. Their confrontation has moved to Earth, where the "Great spark" is hidden, which is a kind of a great force. People also drawn into this eternal confrontation of good and evil.

It is noteworthy that between these two worlds there is a single visual link between the narrative "paths" of the king of the short mummies and his world, and robots. These are their eyes, and if the king is one-eyed and rules over the blind, then the huge eye of Optimus Prime is multiplied into dozens of other machine eyes. The idea that people are "blind" and do not suspect that on their planet there is a battle of cosmic forces for the magic artifact of the "great Spark", and the true reality is seen (and understood) by robot machines is constantly repeated in one or another context in the myth and its film version, and visualized in the clip.

Conclusions Thus, this four-minute visual narrative intertwined and reflected several distinctive features of modern civilization: namely - information chaos, multiculturalism as a way of consuming cultural values; polylocality and further complication of the interaction of reality and various forms of hyper reality; acceleration of mental experiences, approaching the border of visual perception, the presence of hypermyph as a new form of translation of archaic mythologies.

\section{In Search of the Meaning of Hyper Reality Representative Image}

However, is it possible to find the meaning in this spontaneous reflection of modern civilizational features, or is it a complete simulation of it? There is certainly a narrative "path" leading to the meaning in the video, but it's not related to traditional narrative strategies based on the narrative of successive events. Here we are faced with the fact that "events" in the clip (which events cannot be called in the full sense of the term) are arranged in a large-scale spectacle, which aims to open up cultural memory that makes you see something similar to the classic images of "Metropolis" by Fritz Lang, for running athletes Leni Riefenstahl of her "Olympia", on the great Milan fresco by Leonardo, on the
Egyptian mummy, the biblical winged angels.

Moreover, the clip is full of so-called semo-simulations, i.e. signs that are similar in outline to the signs of the ancient civilizations of Egypt and Sumer, but they are not, i.e. there is no meaning behind these figures.

U. Eco studying the mechanisms of influence of the film text on the consumer, considered it possible to distinguish a multi-level structure of visual encoding, isolating codes of perception, recognition codes, transmission codes, tonal codes, iconic codes (including figures, signs, semes), iconographic codes, taste codes, rhetorical codes, stylistic codes and codes of the subconscious. [12] If we consider the original Director's message in the context of a multi-level structure of visual encoding developed by Umberto eco, and if we use his terminology, we can distinguish at least three types of codes: perception codes (dramatic relations between the one-eyed king and the blind), recognition codes (the king has horns growing on his shoulders, hence, this is a fabulous, fantastic character, an allusion to the famous classic drama "The Deer King" by Carlo Gozzi), iconic codes (including symbolic figures - in this case, the presence of snakes in the frame gives a powerful mythocultural reference, starting with the antique Python and ending with the Bible serpent-tempter).

Thus, the entire visual part of the movie text of the clip is a manifestation of the hyperreal in all its features: empty space without its attributes, relativistic discrete time, visual simulacra, deprived of its own meaning, but simulating similarity to images of real cinema and cultural artifacts.

However, if all of the above was a complete content of the clip - this work would not make sense, it would not been viewed by many millions of viewers, besides leaving comments in different languages of the world, among the most repeated in one form or another was the message that the clip is a hymn to hope! What made tens of millions of viewers perceive this clip in such a way? So in the visual simulations was the point? In that case, where did it come from?

\section{Conclusions: The "Third Imagery" in Video}

The music video is characterized by the principle of complementarity. The visual series of a video and a musical work may differ in their content and stylistic characteristics, but together they sometimes make up a bizarre single art object that not only generates elements of the "third imagery", which is not embedded in either the musical work or the visual series, but also gives the artistic image of the clip a special mental taste.

Here it is necessary to recall the philosophy of editing, outlined by S. Eisenstein in his later work "Not Indifferent nature", in which he wrote about the basic algorithm of "production of meaning" in the film text, and identified such a comparison of two elements, in which on the basis of their formal properties, a "third element" appears, qualitatively superior to both original ones. [8]

In our opinion, the" third image " in the clip appeared 
because the Grand visual simulation created within the Hyper/art, which is cinema (since it is generated by nature, a man and a machine, in contrast to the essential arts, binary ones in their ontological basis) met with the traditional, homogeneous arts. This is poetry and music.

Music and lyrics of "Iridescent", co-written by Chester Bennington and Mike Shinoda, come into contradiction, almost in denial of what is unfolding on the screen. The very name of the composition "Descended from the rainbow" refers to early Christian and medieval Byzantine and Orthodox icons, where Christ is depicted sitting on the rainbow. The text of the song is an internal monologue-a prayer that turns to God for help after disappointments, losses, and spiritual devastation.

"When you were standing in the wake of devastation. When you were waiting on the edge of the unknown And with the cataclysm raining down Insides crying,

Save me now!"

You were there, impossibly alone

And in a burst of light that blinded every angel

As if the sky had blown the heavens into stars

You felt the gravity of tempered grace into empty space

No one there to catch you in their arms..." (Bennington/Shinoda, Lyrics, album "Thousand suns», 2010)

Such intentions as "My whole interior screamed -" Save me!", the explosion of light that blinded all the angels, no one is afraid of me in the divine hands" are so traditional that similar rhetorical formulas can be found in hesychastic texts, and in the spiritual exercises of Catholic visionaries. This traditional prayer text makes clear the presence and meaning of the compositional node, which is an allusion to Leonardo da Vinci's fresco "The Last Supper". This event of Sacred history marked the birth of the Church, in which the way to salvation of the soul was opened to every believer through communion.

Perhaps somewhat unexpectedly, the clip's grandiose pseudo-cosmic visual fantasies, accompanied by a calm melody of prayer coming from the depths of a lost, lonely soul, begin to be perceived as a whimsical dream and shadow, which like a curtain closes the exit to the real world. It is symbolic, therefore, that the last frame of the clip is a human hand that slides across the screen, as if opening this curtain of simulacra.

It is the music track and the text that are the elements of existence (about which Paul Virillo wrote, discussing the differences between the artistic image in traditional art and cinema) that finally bring the confused narrative of the clip to the realm of intellectual phantoms, which gives rise to a sense of freedom, hope and the presence of a higher good force and true human reality, which (so far?) do not destroy simulacra and simulations of meanings.[13]

Post scriptum. The lack of meaning in the clip in its traditional, logical understanding may be due to the fact that the music video is a morphological marginal, located on the border of art and design, which performs the function of aestheticizing the virtual space of the clip. Design is the product of a machine for which the problem is meaningless.
I would like to note that the reflection of time in images, or rather, its experience through mentalities - is one of the functions of art and the fact that the clip is capable of visualizing the mentality, once again confirms its aesthetic and artistic status. However, in contrast to art, which has always been quite elitist and reacted to mentalities in culture not so quickly, clip art has the ability to capture an actual dynamic psycho emotional portrait of those who for many centuries called the silent majority."

\section{Notes}

1. Informational letter of the international FILM conference: |TEXT: HISTORY \& STORY in text and film text at the XLVII international philological conference (St.-Petersburg, March 22-25, 2018)

2. In January 2016, the daily number of video views on the site reached about 5 billion people. YouTube has become such a significant phenomenon in the media world that television and media companies have to reckon with it.

3. As an example of the social impact of the video, we can cite the ads of the terrorist organization ISIL, which promoted extremist ideology using an aesthetic image.

4. All seven of Linkin Park's Studio albums have sold more than 1 million copies, and two of these albums have diamond status, i.e. they have sold more than 10 million copies.

5. Similar narrative strategies have been used on television in recent years, for example, in the famous Anglo-American series "Dirk gently's Holistic detective Agency", 2016-2017, dir. Paco Cabezas, Dean Parisot, Michael Patrick Jann, and others. Similar narrative strategies have been used on television in recent years, for example, in the famous AngloAmerican series "Dirk gently's Holistic detective Agency", 2016-2017, dir. Paco Cabezas, Dean Parisot, Michael Patrick Jann, and others.

6. In this text, by incomplete reality, we mean a virtual reality that exists on the border of reality and reality, and its individual elements exist in reality in the form of various objects of the subject environment of culture.

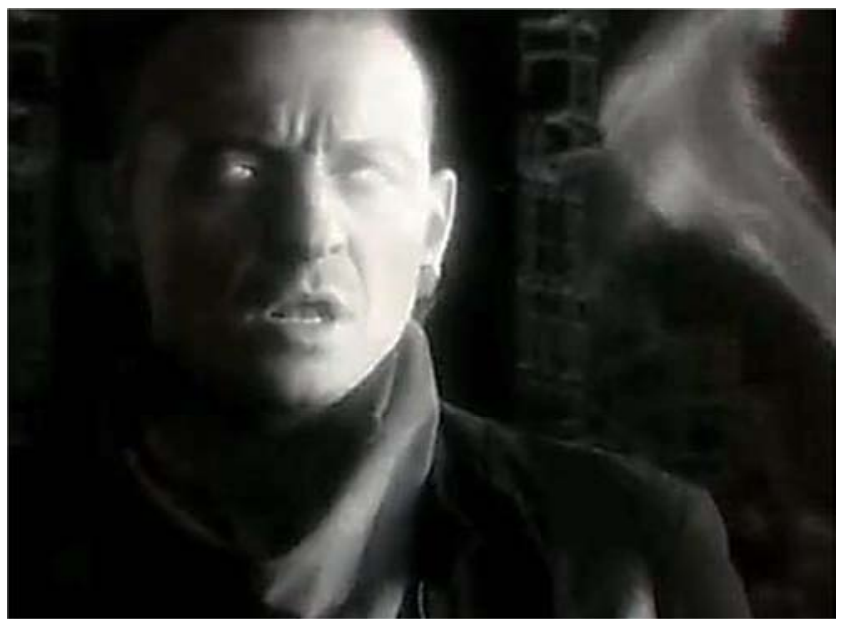

Figure 1. Frame from clip "Iridescent". 


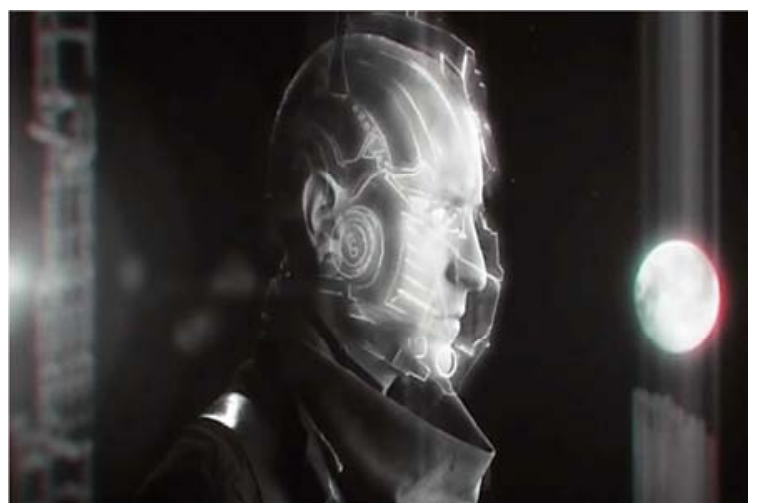

Figure 2. Frame from Fritz Lang's film Metropolis"(1927).

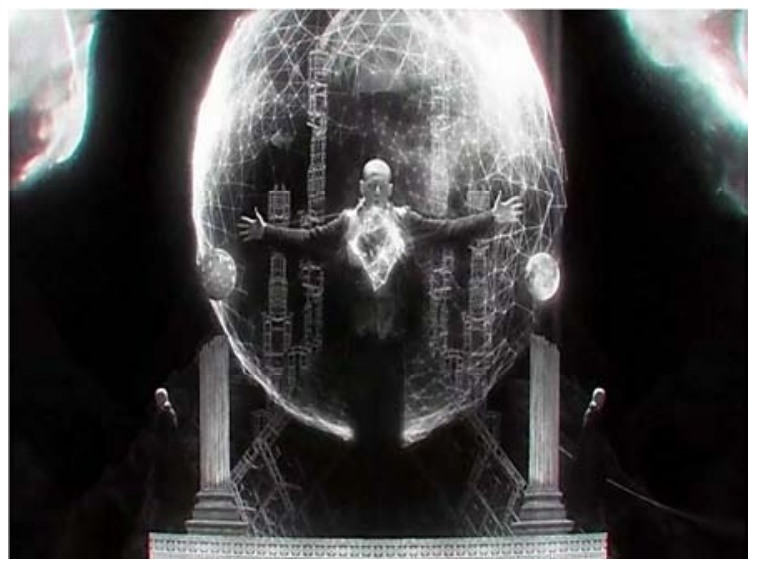

Figure 3. Frame from Fritz Lang's film Metropolis"(1927) .

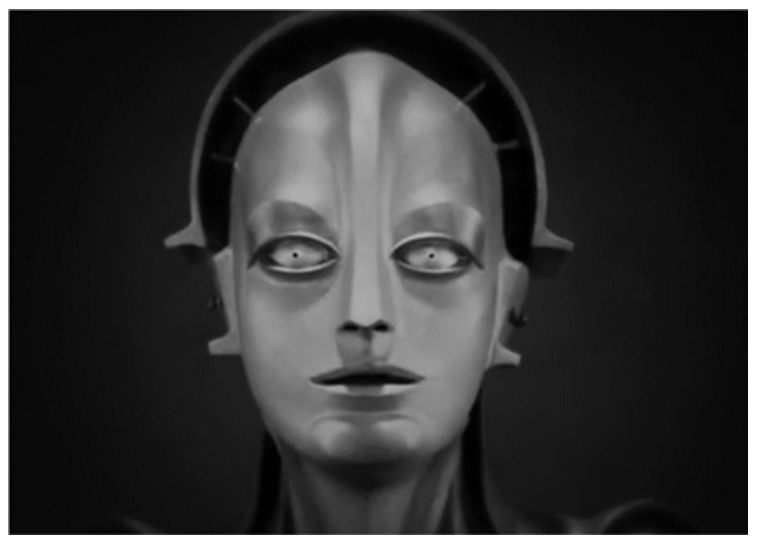

Figure 4. Frame from clip "Iridescent".

Visual and figurative-artistic rollcalls between the frames of the clip and Fritz Lang's film "Metropolis" (1927)

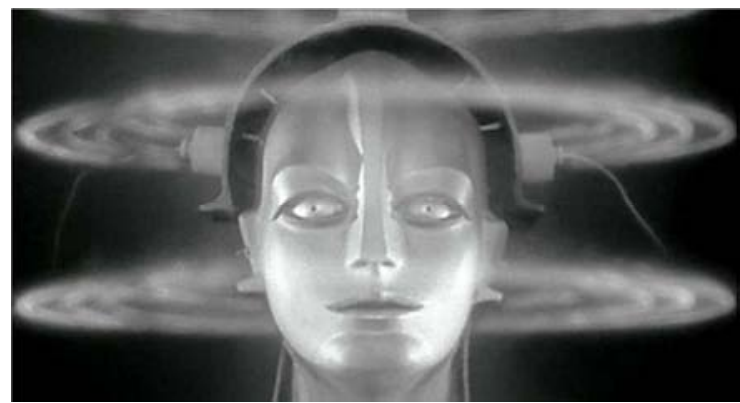

Figure 5. Frame from clip "Iridescent".

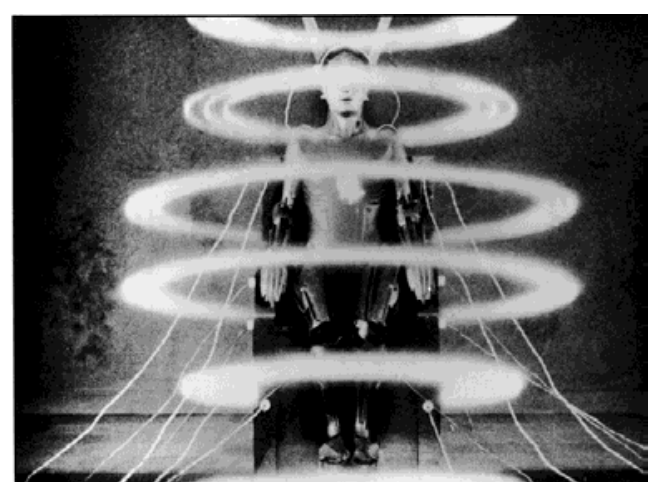

Figure 6. Frame from Fritz Lang's film Metropolis"(1927).

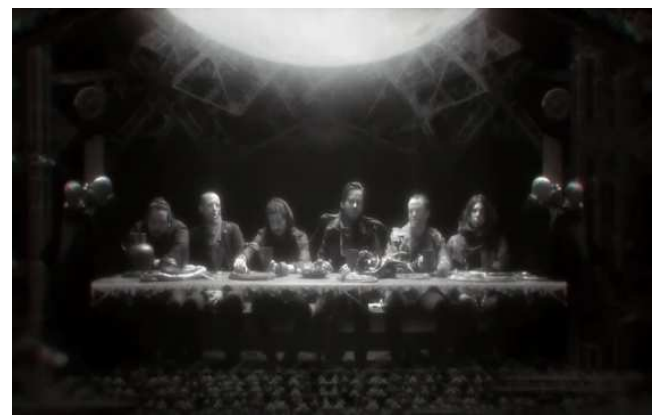

Figure 7. Frame from clip "Iridescent".

Iconographic rollcalls between Leonardo's Milan fresco "The Last Supper" and the Central frame of the clip "Iridescent"

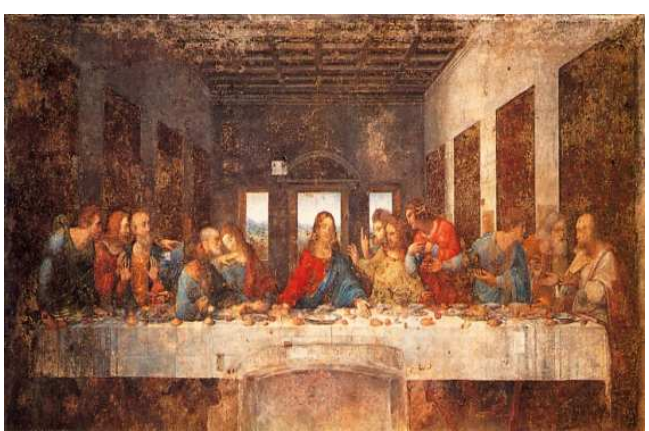

Figure 8. Leonardo's Milan fresco "The Last Supper".

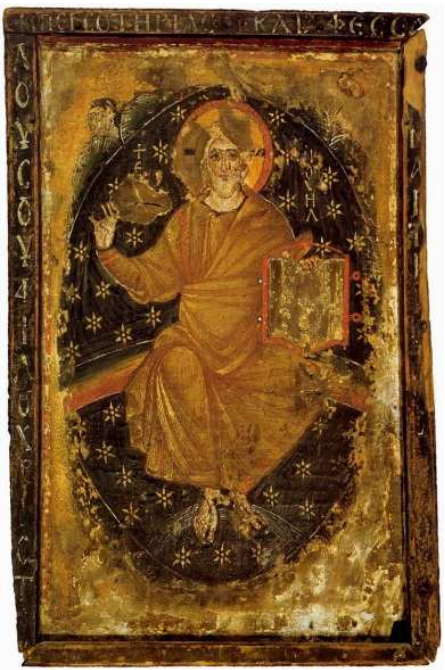

Figure 9. Early Byzantine icon "Christ in the forces" (Iridescent). 


\section{References}

[1] Kurennoy, V. A. film Philosophy: exercises in analysis. - M.: New literary review, 2009, p. 232.

[2] Foortai, F. the Phenomenon of clipping in contemporary mass culture: an attempt of cultural analysis. // Bulletin of the Leningrad state University named after A. S. Pushkin. No. 4, Vol. 1. (Philosophy Series). - SPb., LSU, 2009, P. 126-135.

[3] Cook, D. A History of Narrative Film. «W. W. Norton \& Company», New York- London. 1995, 864 p.

[4] Langer Suzanne K. Feeling and Form. Rout ledge and Kegan Paul. London. 1953, 423 p.

[5] Jameson, F. Postmodernism, or, The Cultural Logic of Late Capitalism. «Duke University Press», Durham, 1992, 451p.

[6] Goodwin, A. Dancing in the Distraction Factory: Music Television and Popular Culture, «Rout ledge», London. 1993, $237 \mathrm{p}$.

[7] Clip as a leading language of mass communication: opportunities and limits of Analytics (materials of the theoretical seminar). Access mode: http//www.//anthropology.ru/projects/media/seminars/2002

[8] Eisenstein S. Not Indifferent nature. Volume 2: on the structure of things/Comp. N. Kleiman. M.: Eisenstein center; Museum of cinema, 2006, $624 \mathrm{p}$.

[9] Sorokin, Yu. A., Tarasov, E. F. (1990). Creolized texts and their communicative function. // Optimization of speech impact. - M.: Higher school, 1990, P. 180 - 186.

[10] Eco. U. Baudolino, Bompiani, 2000, 528 p.

[11] Baudrillard, J. Simulacres et simulation. Paris: Galilée, 1981, $240 \mathrm{p}$.

[12] Eco U. Articulations of the Cinematic Code, in Nichols B. (ed.) Movies and Methods. An Anthology (Berkley \& Los Angeles: University of California Press, 1976, P. 590-607.

[13] Virilio P. La machine de vision, , 1988 г. Éditions Galilée, 1988, $144 \mathrm{p}$.

[14] Elsaesser Th. and Hagener M., Film Theory: An Introduction through the Senses. Routledge, London, 2010. 226 p.

[15] The term «hypermyth» introduced by Francisca Foortai. Development of the concept and its individual provisions in the works:// Design myth and the myth of design. Philosophy of the new art style.//Strategies of ethical and aesthetic reflection: Proceedings of the all-Russian conference on November 18-19, 2005-Saint Petersburg: 2006-pp. 220-224.
[16] Art of mass culture as a source of its study.//Bulletin of the Leningrad State University n. a. A. S. Pushkin. No. 2 (11) Series of philosophy. Saint Petersburg: LSU, 2008, pp. 108119.

[17] Cimmerian shadows at the dawn of epic fantasy (on the question of the social role of the movie hero in popular culture). // "Antropotopos" - theoretical journal in the field of philosophical Sciences. - № 1-2, Omsk, 2008. - p. 89-94.

[18] Phenomenon of virtuality in mass culture or Welcome to our nightmare.// Bulletin of the Leningrad state University n. a. A. S. Pushkin. No. 3, volume 2 (Philosophy Series). Saint Petersburg: LSU, 2009, pp. 112-120.

[19] The phenomenon of clipping in modern popular culture: attempt of cultural analysis. // Bulletin of the Leningrad state University n. a. A. S. Pushkin. No. 4, Vol. 1 (Philosophy Series). Saint Petersburg: LSU, 2009, pp. 126-135.

[20] Night and Day as archetypes of a large artistic style.//Bulletin of the Leningrad state University n. a. A. S. Pushkin. No. 3, Vol. 2 (Philosophy Series). - Saint Petersburg: LSU, 2010. - p. 219-225.

[21] Cult of the eye "and "packing effect". An art object in contemporary art. //International journal of cultural research. International Journal of Cultural Research, "Art theory and artistic imagination of the twenty-first century", №2 (3), 2011c. 44-55. Access mode: http//www.Cultural research.ru.

[22] On the question of the archetypal continuity of neo-Gothic. // Omsk scientific Bulletin: series philosophy, psychology, social sciences, cultural studies and art criticism. - №1. 2012, Omsk, 2012-P. 213-223.

[23] Cinema of the XXI century: twilight zone. // Bulletin of the Leningrad state University n. a. A. S. Pushkin. No. 3, Vol. 2 (philosophy Series). - Saint Petersburg: LSU, 2011. - p. 222229.

[24] "Digital folklore" as a new socio-cultural and artistic phenomenon. //"Cultural Sciences in the perspective of digital humanities": proceedings of the international conference. Scientific Conf., October 3-5, 2013/edited by L. V. Nikiforova, N. V. Nikiforova. - St. Petersburg: Asterion, 2013. - p. 290-296 (600 p.).

[25] Trailer as a borderline form of cinema text: apophatica of the narrative and enigmaticity of the image. // VI international conference "Actual issues of theory and practice of art" "Actual problems of theory and practice of art"// conference Materials, Moscow: 2015, P. 27.

[26] Specifics of art space in borderline types of film text.// VII international conference "Actual issues of theory and practice of art" "Actual problems of theory and practice of art"// conference Materials, St.Petersburg: 2016, P. 341. 